УДК $811.111 .+81 ’ 25$

DOI https://doi.org/10.26661/2414-1135-2021-84-8

\title{
ПОВТОРНИЙ ПЕРЕКЛАД ЯК ВИД ПЕРЕКЛАДАЦЬКОГО ДИСКУРСУ
}

\author{
Гриців Н. М. \\ кандидат філологічних наук, доцент, \\ дочент кафедри прикладної лінгвістики \\ Начіональний університет «Львівська політехніка» \\ вул. Степана Бандери, 12, Львів, Україна \\ orcid.org/0000-0001-6660-7161 \\ nataliia.m.hrytsiv@lpnu.ua \\ Галабурка В. В. \\ магістриня кафедри прикладної лінгвістики \\ Інститут комп 'ютерних наук та інформаційних технологій \\ Національного університету «Львівська політехніка» \\ вул. Степана Бандери, 12, Львів, Україна \\ orcid.org/0000-0002-5239-9266 \\ viktoriia.halaburka.mfl.2020@lpnu.ua \\ Загора K. C. \\ магістриня кафедри прикладної лінгвістики \\ Інститут комп'ютерних наук та інформаційних технологій \\ Національного університету «Львівська політехніка» \\ вул. Степана Бандери, 12, Львів, Україна \\ orcid.org/0000-0002-6121-5406 \\ karyna.zahora.mfl.2020@lpnu.ua
}

\footnotetext{
Ключові слова: переклад, феномен повторного перекладу, культура, ретранслячія, причини здійснення повторного перекладу.
}

Стаття присвячена аналізу необхідності дослідження феномену ретрансляції, чи повторного перекладу, який є невіддільною частиною сучасного перекладацького дискурсу. Існування в певній національній культурі кількох перекладів того самого іншомовного літературного твору, який в оригіналі має зазвичай одне текстове втілення, у вітчизняному перекладознавстві отримало назву «перекладацької множинності». I хоча пересічний читач рідко замислюється над доцільністю нового перекладу вже відомого в цільовій культурі твору, цей феномен детально досліджується європейськими та американськими дослідниками, хоча вітчизняна лінгвістика поки що його оминає. Переклад - це складний та багатогранний процес, який змушує перекладача стикатися з чужою мовною культурою та необхідністю перенаправити смисл написаного в вихідній культурі до цільової культури. Переклад твору, який вже колись було перекладено для однієї або іншої культури, має свої складності: постає питання про цінність повторного перекладу, адже повторний переклад залишається актуальним попри майбутні повторні переклади твору - під час здійснення кожної нової ретрансляції використовуються різноманітні стратегії лінгвокультурної адаптації. Можемо стверджувати, що мова та культура по-різному взаємодіють одна з одною в кожному наступному перекладі. Підкреслюється важливість текстових, паратекстуальних та констектуальних даних під час здійснення повторного перекладу. Завдяки аналізу наявних перекладів та переоцінці сучасної літератури, що стосується феномену повторного перекладу, в статті досліджується, 
як прийняття певних соціологічних чинників може обгрунтувати мотивацію щодо здійснення повторного перекладу.

Дослідження перевіряє обгрунтованість необхідності повторного перекладу та демонструє, що не тільки лінгвістичні фактори, а й соціологічний вплив має велике значення під час мотивації щодо здійснення повторного перекладу. Також важливо дати чітке визначення тому, що таке повторний переклад, та виділити його риси, особливості та роль у будуванні культурних / літературних норм. Однак треба визнати, що в цьому питанні ще далеко до одностайності, і намагання комплексно підійти до вирішення проблеми множинності художніх перекладів з урахуванням міркувань різних теорій та гіпотез визначає актуальність цієї розробки.

\title{
RETRANSLATION AS A TYPE OF TRANSLATION DISCOURSE
}

\author{
Hrytsiv N. M. \\ Candidate of Philological Sciences, Associate Professor, \\ Associate Professor at the Department of Applied Linguistics \\ Lviv Polytechnic National University \\ Stepana Bandery str., 12, Lviv, Ukraine \\ orcid.org/0000-0001-6660-7161 \\ nataliia.m.hrytsiv@lpnu.ua \\ Halaburka V. V. \\ Master Student at the Department of Applied Linguistics \\ Institute of Computer Sciences and Information Technology \\ of Lviv Polytechnic National University \\ Stepana Bandery str., 12, Lviv, Ukraine \\ orcid.org/0000-0002-5239-9266 \\ viktoriia.halaburka.mfl.2020@lpnu.ua \\ Zahora K. S. \\ Master Student at the Department of Applied Linguistics \\ Institute of Computer Sciences and Information Technology \\ of Lviv Polytechnic National University \\ Stepana Bandery str., 12, Lviv, Ukraine \\ orcid.org/0000-0002-6121-5406 \\ karyna.zahora.mfl.2020@lpnu.ua
}

Key words: translation, phenomenon of retranslation, culture, retranslation, motives of retranslation.
The article focuses on the analysis of the necessity to study the phenomenon of retranslation, which is an integral part of modern translation discourse. The existence of several translations of the same literary work in a certain culture, which has, as a rule, one textual embodiment, in Slavic translation studies has been called the "translation plurality". This phenomenon is being studied in detail by European and American researchers, while domestic linguistics has so far bypassed the phenomenon of retranslation. And although the average reader does not think about the necessity of a new translation of a work already known in the target culture, researchers in translation studies are trying to investigate in detail and promote the phenomenon of retranslation. Translation is a complex and multifaceted process that forces the translator to face a foreign language culture and the necessity of redirecting the meaning of what is written in the source culture to the target culture. The translation of a work that has once been translated for one culture or another has its difficulties: the question of the value of retranslation arises, because retranslation remains relevant despite future retranslations of the work in question - each new retranslation 
uses different strategies of linguistic and cultural adaptation. We can say that language and culture interact differently with each other in each subsequent translation, emphasizes the importance of textual, paratextual and contextual data in re-translation. Due to the analysis of existing translations and reassessment of modern literature related to the phenomenon of retranslation, the article examines how the adoption of certain sociological factors can justify the motivation for retranslation. The study examines the validity of the need for retranslation, and demonstrates that not only linguistic factors but also sociological influence is of great importance in motivating retranslation. However, it should be recognized that this issue is still far from unanimous, and an attempt to comprehensively approach the solution of the problem of the plurality of literary translations, taking into account considerations of various theories and hypotheses, determines the relevance of this development.

Постановка проблеми. Активний розвиток перекладацького дискурсу в дослідженнях іноземних вчених результував в розширенні його традиційних меж та уявлень, в появі нових термінів, які позначали не тільки вже давно відомі поняття, а й явища, які довгий час були на периферії наукового інтересу. До них зараховують поняття повторного перекладу, чи ретрансляції, що є калькою з французьского "retraduction".

Попри те, що феномен повторного перекладу не $\epsilon$ новим явищем, він довго залишався непоміченим лінгвістами. Кількість вітчизняних досліджень, які стосуються цього феномену, є надзвичайно малою, якщо порівнювати їі 3 кількістю європейських чи американських досліджень. Можна стверджувати, що повторний переклад це одне 3 найчастіших та найприродніших явищ майже в кожній галузі перекладу, особливо в художньому перекладі.

Вивченню феномену повторного перекладу приділяли увагу такі зарубіжні лінгвісти, як А. Берман, I. Гамб'є, С. Сузам-Сараєва, Дж. Вандор, Ш. Дін-Кокс, П. Бенсімон, Р. Шульте та Дж. Бігнет, Е. Пим, С. Басснет.

Метою статті $\epsilon$ дослідження феномену повторного перекладу як соцільно-локалізованої діяльності. Далі подаватимуться доказові матеріали щодо необхідності практики повторного перекладу в літературі, а саме під час перекладу англомовних творів українською.

Методи дослідження представлені методом аналізу, методом синтезу, описовим методом i зіставним методом. Перший передбачає поділ цілого на частини та опис кожної з частин та зв'язків, які виникають між ними; другий - поєднання частин у цілісну систему. За допомогою описового методу виявляли та описували всіх досліджувані одиниці, їх особливості та функції. Зіставний метод спрямований на виявлення загальних та специфічних рис зіставлюваних одиниць.

Результати дослідження. На початку 90-х років минулого століття науковці розглядали процес здійснення повторних перекладів як недостатньо досліджений феномен $[1 ; 2]$. Це сприйняття залишалось незмінним до початку XXI століття, коли феномен повторних перекладів почав отримувати серйознішу увагу від дослідників
[3; 4; 5]. Згідно з Бенсімоном [6] процес повторного перекладу текстів почав цікавити науковців після певних пропозицій німецького дослідницького центру художнього перекладу (Georg-AugustUniversität Göttingen "Die literarische Übersetzung”, 1985-1997). Вони мали на меті розглянути феномен повторного перекладу текстів 3 огляду на його внутрішню та зовнішню історію. Перший термін стосується вивчення та аналізу текстово-лінгвістичних профілів перекладених текстів 3 точки зору їх послідовних переформулювань через повторний переклад. Під терміном «зовнішня історія» розуміємо ідентифікацію (розпізнавання) творів та визначення частоти процесу повторного перекладу як доповнення до інших актуальних проблем, пов'язаних із контекстом. Інакше кажучи, увага зосереджується на ідентифікації робіт, які були перекладені. Зокрема, коли, ким та скільки разів конкретна робота була перекладена та за яких умов відбувся переклад.

В 1990 році теоретичні припущення, що лежать в основі гіпотези щодо необхідності повторних перекладів, були представлені французьким мовознавцем Антуаном Берманом у статті "La retraduction comme espace de la traduction" [1], чия позиція щодо повторних перекладів є основою так званої гіпотези щодо необхідності повторних перекладів. Згідно з Берманом «в цій галузі суттєвої «недосконалості», яка характеризує переклад, лише через повторні переклади можна, іноді, досягти ідеалу». Він акцентує увагу на проблемі «3 плином часу застарілих перекладів та непідвладних часу вихідних текстів», а також підкреслює, що «переклад - це діяльність, яка підвладна часу, діяльність, яка має власну темпоральність».

Гіпотеза щодо необхідності повторних перекладів переважно стосується тільки художнього перекладу. Згідно з Берманом переклад художніх текстів $€$ «незакінченою» дією, яка може розвиватись тільки завдяки пізнішим версіям перекладу вихідного тексту. Він стверджує, що «закінченість» в цьому контексті стосується успішного наближення перекладу до вихідного тексту та відображення зустрічі між перекладачем та вихідною мовою. Інакше кажучи, перші переклади прагнуть до цілі «переклад заради перекладу», тоді як повторні переклади зазвичайф орієнтовані 
на джерело, зближують читачів з вихідним текстом, його мовою та культурою. Берман зазначає, що «можливість створити якісний переклад з'являється тільки після первинного перекладу, зробленого наосліп».

Берман стверджує, що всі переклади відзначаються властивою для них «невдачею», невдачею яка досягає критичної точки у вступному перекладі, який прагне інтегрувати одну культуру в іншу для того, щоб гарантувати позитивний прийом твору в цільовій культурі. Однак у подальших перекладах, на його думку, більше уваги приділяють змісту та стилю вихідного тексту, а також зберігають культурну дистанцію між перекладом та текстом оригіналу, тим самим підкреслюючи неповторність вихідного тексту. Можемо стверджувати, що деякі повторні переклади $є$ ближчими до вихідного тексту та відповідають потребам сучасних читачів краще, ніж перші переклади. Однак логічність гіпотези щодо необхідності повторних перекладів залежить суто від фактору часу, а саме від періодів часу між кожним процесом перекладу. Інакше кажучи, ця гіпотеза стосується лише перекладів того ж самого цільового тексту, які були здійснені через довгі часові паузи. Таким чином, не можна стверджувати, що ця гіпотеза буде валідною, якщо ії̈ застосувати до різних повторних перекладів, які були здійснені протягом короткого відрізку часу, оскільки кожен з цих перекладів мав справу з тим самим періодом часу та контекстом.

Гіпотеза щодо необхідності повторних перекладів опирається на модель ідеалізму, яка передбачає, що чим далі ми відійдемо від періоду створення вихідного тексту, тим кращим буде наш переклад [4]. Згідно 3 цією гіпотезою повторні переклади художніх текстів необхідні, адже немає досконалих перекладів [1]. Інакше кажучи, чим більше здійснюється перекладів одного тексту, тим кращі результати ми отримуємо, тим самим допомагаючи перекладу досягти «ідеальної ідентичності з оригіналом» $[7$, с. 61$)$.

Дін-Кокс [5, с. 66-74] зазначає, що «в першу чергу головні мотиви акту повторного перекладу виникають від внутрішніх (лінгвістичних та культурних) та зовнішніх (пара- та позатекстуальних) змінних». Вона звертає особливу увагу на важливість аналізу лінгвістичних, культурних, паратекстуальних та позатекстових матеріалів, адже вони використовуються як «місце доказу соціологічних причин повторного перекладу та як вказівка на природу будь-яких взаємодій, які можуть відбуватися між різними версіями».

Повторний переклад також може відбуватися в одному часовому періоді. Згідно 3 Дін-Кокс [5, c. 1], «реагуючи на різноманітні контекстні впливи та обмеження, деякі 3 них розділяються в часовому просторі періодами, які в деяких випадках можуть тривати досить довго, але є випадки, коли це може відбуватися синхронно». Синхронні повторні переклади можуть бути створені 3 метою, щоб запропонувати іншу візуалізацію або інтерпретацію оригіналу, а також, щоб звернутися до іншої цільової аудиторії.

Досліджуючи процес повторного перекладу, важливо розрізняти два основні типи повторного перекладу: діахронічний та синхронічний. Діахронічний повторний переклад стосується перекладів одного тексту, які були зроблені в різні часові періоди, тоді як синхронічний повторний переклад стосується тих перекладів, які були зроблені в однаковий часовий період, наприклад, протягом десяти років. Дослідження процесу повторного перекладу варто починати 3 вивчення причин існування діахронічного повторного перекладу, адже він є найрозповсюдженішим, і лише потім переходити до дослідження синхронічного типу. У 90-х роках минулого століття у дослідників перекладу часто виникало питання, чому деякі переклади швидко ставали застарілими, водночас як інші досі продовжують вважатися «класикою» у своїх перекладених версіях $[1 ; 8 ; 2]$. Берман [1, с. 1-7] стверджує, що переклад це «незакінчений процес», і що тільки здійснення повторних перекладів протягом певних часових відрізків може перетворити цей процес на завершений. Він визнає, що перші переклади застарівають, а отже, постійно виникає потреба нових перекладів. Він зазначає, що кожному перекладу вдається не тільки наблизитися до вихідного тексту, а й гідно відобразити зустріч між перекладачем та мовою оригіналу [1, с. 3]. Гамб'є [2] порушує питання частоти та періодичності створення повторних перекладів. На його думку [2, с. 413], «повторні переклади приносять зміни оскільки все змінилося». Він зазначає, що час відіграє ключову роль у наданні детальнішого пояснення повторних перекладів 3 точки зору відстані у часі по відношенню до вихідного тексту, чи часу, який пройшов між першим перекладом та наступними повторними перекладами. Гамб'є відмічає, що повторний переклад здійснювати легше, оскільки 3 плином часу цільова мова та культура стає відкритішою та терпимішою до імпортованих дискурсивних елементів [2, с. 416]. Це пояснюється тим, що зазвичай, якщо 3 моменту останнього перекладу певного тексту минув тривалий відрізок часу, то в цільовій системі найімовірніше вже відбулося багато змін в історичній, культурній та мовній ситуації. Згідно з Гамб'є повторний переклад «залежить від еволюції цільової аудиторії, іiі смаків, потреб та навичок». Його позиція визначає модель повторного перекладу як постійне удосконалення протягом певного періоду часу. 
Згідно з Шульте та Бігнет [7, с. 61-63] є три етапи перекладу вихідного тексту протягом певного періоду часу. Під першим етапом розуміємо «знайомство читачів цільової культури 3 невідомим» 3 погляду та досвіду перекладача. На другому етапі перекладач намагається «пережити на власному досвіді чужоземну ситуацію, але насправді лише привласнює чужу ідею та видає iii за власну». Третій етап продукує найкращий переклад, оскільки метою є «досягти ідентичної схожості з оригіналом» та «в кінцевому результаті значно полегшити розуміння вихідного тексту».

Повторний переклад може надати свіжий погляд на розуміння вихідного тексту, тобто нові знання про роботи, авторів та культури, які нас цікавлять, що дозволить створити високоякісний переклад.

Гамб'є [2, с. 414] вважає, що повторний переклад може запропонувати нам «нову інтерпретацію вихідного тексту, оскільки перекладач детально досліджує феномен цільової культури та вихідного тексту».

Зважаючи на те, що художній переклад - це витвір мистецтва та креативності, а мистецтво завжди завдавало клопоту перекладачам, процес повторного перекладу є стабільно тривалим. Феномен повторного перекладу зазвичай цікавить науковців, які планують видавати роботи, що стосуються історії літератури. В межах різноманітних літературних форм та жанрів повторно перекладаються саме класичні твори, адже вони користуються визнанням у цільовій культурі, тобто в культурі, яка взялась за переклад твору.

Суб'єктивність перекладача та його особиста оцінка цього твору та роботи або незадоволеність естетичною функцією літературного тексту, яка передана в попередніх перекладах, є основними причинами для повторного перекладу класичних творів. Літературні тексти також можуть бути перекладені повторно з метою, щоб створити переклад для іншої функції, до прикладу для створення спрощеної версії для дитячого видавництва [5, ст. 14]. Басснет [9] стверджує, що час та жанр грають основну роль у мотивації літературного повторного перекладу: прийнято вважати, що п'єси вимагають повторного перекладу через регулярні проміжки часу, зазвичай це кожні 20 років. Цьому припущенню немає жодного логічного пояснення, але справді здається, що усне мовлення старіє швидше, ніж письмова мова, а оскільки п'єса - це своєрідне розшифрування скрипту, з цього слідує, що процес старіння буде більш помітний у п'єсі, ніж в інших типах письмових текстів.

Деякі науковці підкреслюють важливу роль соціокультурних факторів та визначають низку причин для виконання художнього перекладу [12].
За Ландерсом [10, с. 5-6], деякі художні перекладачі шукають престижу, тоді як інші намагаються розвиватись «у науці», оскільки вдалий переклад може привести до «звернення до інших літераторів у тому самому колі». Він також підкреслює, що головною мотивацією для виконання художнього перекладу є гроші, краща грошова винагорода очікує на перекладачів в інших галузях перекладу. Стверджується, що повторний переклад сприяє відродженню інтересу до давно забутого художнього тексту, та видавці можуть використовувати повторні переклади як позитивний літературний та комерційний інструмент, якщо викладач $\epsilon$ престижним та досяг визнання в цільовій культурі. Басснет [9] стверджує, що повторний переклад допускається з п'яти причин: по-перше, наявний переклад $є$ незадовільним $з$ точки зору помилок в інтерпретації, через зміни мовних норм протягом років; по-друге, якщо виходить нове видання вихідного тексту, яке стає стандартним посиланням; по-трете, якщо наявний цільовий текст зі стилістичної точки зору вважається застарілим; по-четверте, якщо повторний переклад має спеціальну функцію для заповнення в цільовій мові; по-п'яте, якщо інша інтерпретація вихідного тексту $є$ обгрунтованою. Згідно 3 Пимом [12] ні лінгвістичні зміни, ні старіння тексту не $\epsilon$ задовільними для пояснення причин, що лежать в основі процесу повторного перекладу вихідного тексту. Він аргументує свою концепцію «активного перекладу», де мотивація для початку нового перекладу повністю пов'язана 3 тим, що перекладач бере до уваги існування попередніх перекладів; таким чином, створюючи «активне суперництво між різними версіями» [12, с. 83]. «Пасивний повторний переклад» - ще одна концепція Пима, яка стосується ситуації, коли перекладачі можуть не знати про наявність більш раннього перекладу. Порівнюючи пасивний та активний повторний переклад, Пим зазначає, що «пасивний повторний переклад» відображає зміну ставлення цільової культури і може протистояти переконанням двох культур, тоді як «активний повторний переклад» вважається результатом конфліктів між людьми або групами в цільовій культурі [12, с. 84-85]. Прикладами активних повторних перекладів, які описує Пим, є: різні версії вихідного тексту для різних груп читачів, замовлений переклад для виправлення лінгвістичних помилок у попередній версії.

Зазвичай перекладачі не беруть до уваги особливості дискурсу, адже вважають, що вони $\epsilon$ неважливими для процесу перекладу. Помилково вважати, що головним завданням перекладача $\epsilon$ більш-менш дослівне відтворення речень цільовою мовою. До прикладу, дослівний переклад приказки "They locked the barn door after the horse 
had been stolen" не матиме сенсу в більшості місцевих мов країн Африки, адже більшість людей не володіє кіньми або сараями.

Деякі посібники 3 перекладу містять в собі помилкову думку, що поняття перекладу - це ймовірніше про переклад 3 мови на мову, а не про переклад тексту як системи, що несе певну інформацію. Вони надають інформацію про різні семантичні домени, перераховують відповідні граматичні структури та аналізують відмінні стилістичні прийоми досліджуваних мов. Але це швидше є завданням лінгвіста, який аналізує мову ззовні. Тоді як завданням перекладача $є$ внутрішній аналіз, а саме: робота 3 контекстом опрацьованого тексту. Під час перекладу перш за все необхідно звертати увагу на контекст, адже він може бути не тільки експліцитним, тобто явно вираженим вербальними і невербальними засобами, а також й імпліцитним - явно не вираженим, де важливими $\epsilon$ фонові знання комунікантів про попередні ситуації або знання попередніх текстів [3, c. 67-70]

Складнішим є перекладати текст, який вже $\epsilon$ перекладом 3 якоїсь мови. Деякі перекладачі помилково вважають, що їхнім завданням є лише переклад 3 мови-перекладу на цільову мову. Але перекладач також має звернути увагу на те, що якщо попередній перекладач допустив очевидні смислові чи граматичні помилки під час перекладу, то не варто відображати ці помилки у власному перекладі. Професійні перекладачі зазвичай або виправляють ці помилки самостійно, або звертають на них увагу тих, хто відповідальний за здійснення перекладу оригінального тексту.

Під час здійснення перекладу досвідчені перекладачі також можуть значно покращити стиль та організацію дискурсу, адже вони майже завжди більш досвідчені в справах стилістики, аніж автори документів, які подані на переклад. До прикладу, коли керівники програми перекладів $€ С$ порівнюють один й той самий документ, представлений різними мовами, стає зрозумілим що форма документу однією мовою може поступатись формі документа іншою мовою. В таких випадках стилістично неповноцінним документом найчастіше виступає саме оригінал документу.

Основними компонентами тексту зазвичай вважають часові та просторові межі, взаємозв'язок подій, діалоги та літературні формули. Швидке розпізнавання таких особливостей та їхньої функції в дискурсі сприяє роботі перекладача. За допомогою такого аналізу можна дізнатися, які особливості мовної культури присутні в оригінальному тексті та чи $\epsilon$ вони релевантними для цільової мовної культури. До прикладу, низка традиційних китайських романів та новел мають нещасливу кінцівку, тому, аби привабити амери- канську аудиторію, видавці повинні працювати над зміненням сумної кінцівки, адже зазвичай американці надають перевагу історіям зі щасливим кінцем.

Фізичний простір зазвичай розглядають через призму трьох вимірів - висоти, ширини та глибини. В деяких мовах існують інші просторові відносини, які розглядають як вимір, до прикладу: above, below, behind, in front of, near, around. Дискурсивний простір часто пов'язують 3 комунікатором, але він також може мати зв'язок з позицією домінуючого персонажу історії- одним із прикладів можна вважати розташування Iсуса в деяких розповідях Євангелія.

Посилання на простір також зустрічаються в дієсловах руху, до прикладу: come, go, arrive, leave, return, enter, exit та мінливість значень в певних контекстах залежить від значення інших слів.

Великі відстані зазвичай повинні розраховуватись 3 точки зору часу, як, наприклад, «світові роки», але в деяких культурах навіть короткі відстані вимірюють 3 точки зору часу. В Швейцарії відстань між двома точками на маршрутах зазначають в годинах та хвилинах. Тоді як у Німеччині аналогічні просторові відстані вказують у кілометрах.

Проте переклад виразів, що стосуються простору та часу, може створити значні проблеми для перекладача, якщо певні цифри мають символічне значення. Яскравим прикладом можна вважати 12000 стадій - довжину, ширину та висоту столиці Царства Божого, описаної в «Одкровенні» Іоанна Богослова. Еквівалентом 12000 стадій $є$ 2200 кілометрів, але в іудаїзмі та християнстві число 12 має сакральне значення - 12 учнів Ісуса, які згодом стали апостолами, 12 років було Ісусу Христу, коли він залишився в храмі та почав дивувати вчителів своєю мудрістю. Але передача цієї старовинної одиниці виміру в реаліях сучасних одиниць просторових вимірів може значно зашкодити тексту, адже відразу втрачається те сакральне значення числа 12 , яке було зазначене вище. Для таких випадків $\epsilon$ доречним використання приміток, які допоможуть читачеві зрозуміти, про що йдеться в тексті.

\section{BIBLIOBRAPHY}

1. Berman A. La retraduction comme espace de la traduction. Palimpsestes. 1990. № 4. P. 1-7. DOI: https://doi.org/10.4000/palimpsestes.596.

2. Gambier Y. La retraduction, retour et détour. Meta : Journal des traducteurs. 1994. No. 3 Vol. 39. P. 413-417. DOI: https:// doi.org/10.7202/002799ar.

3. Susam-Sarajeva Ş. Multiple-entry visa to travelling theory: Retranslations of literary and 
cultural theories. Target. International Journal of Translation Studies. 2003. No. 1 Vol. 15. P. 1-36. DOI: https://doi.org/10.1075/target.15.1.02sus.

4. VándorJ.Adaptation and Retranslation. Budapest: (PhD Thesis Summary), 2010. 9 p. URL: http:// doktori.btk.elte.hu/lingv/vandorjudit/thesis.pdf.

5. Deane S. Confronting the Retranslation Hypothesis: Flaubert and Sand in the British Literary System. Edinburgh: (PhD Thesis), 2011. $320 \mathrm{p}$.

6. Bensimon P. Présentation. Palimpsestes. 1990. № 4. P. 9-13. DOI: https://doi.org/10.4000/ palimpsestes.598.

7. Biguenet J., Schulte R. Theories of Translation: An Anthology of Essays from Dryden to Derrida.
Chicago: The University Of Chicago Press, 1992. $260 \mathrm{p}$.

8. Rodriguez L. Sous le signe de Mercure, la retraduction. Palimpsestes. 1990. № 4. P. 63-80. DOI: https://doi.org/10.4000/palimpsestes.604.

9. Bassnett S., Lefevere A. Constructing Cultures: Essays on Literary Translation. Clevedon: Multilingual Matters, 1998. $143 \mathrm{p}$.

10. Landers C. Literary Translation: A Practical Guide. Clevedon: Multilingual Matters, 2001. 224 p.

11. Nida E. Contexts in Translating. Amsterdam/ Philadelphia: John Benjamins Publishing Company, 2001. 125 p.

12. Pym A. Method in translation history. Manchester : St. Jerome, 1998. 220 p. 